\title{
Sistema Único de Assistência Social e Sistema de Justiça: explicitando problemáticas e orientações a psicólogas(os)
}

\author{
Sistema Único de Assistência Social \\ (Brazilian Social Service System) and Justice: \\ explaining problems and guidance to \\ psychologists
}

Pablo Mateus dos Santos Jacinto

Centro Universitário Jorge Amado (Salvador). Bahia, Brasil. pablojacintopsi@gmail.com

RESUMO | OBJETIVO: Este estudo trata-se de uma pesquisa documental que teve como objetivo apresentar uma análise crítica sobre a relação entre o Sistema Único de Assistência Social (SUAS) e o Sistema de Justiça brasileiro (S)), com foco na atuação da psicologia. MÉTODOS: Foram analisados oito documentos oficiais adotados pelo Sistema Conselhos de Psicologia como referência para orientação. Utilizou-se o suporte do software MAXQDA para análise. Buscou-se responder a três questões: (a) Como ocorre a relação entre o SUAS e o SJ? (b) Quais os impactos das demandas do SJ na organização do trabalho da(o) psicóloga(o) no SUAS? (c) Quais posicionamentos e orientações o Sistema Conselhos de Psicologia adota perante essa questão? RESULTADOS: Constatou-se que a atuação da psicologia no SUAS em interface com o SJ envolve atividades previstas, como a execução de medidas socioeducativas e participação em audiências, mas frequentemente é acometida com demandas que extrapolam o planejamento, incluindo realização de perícias, avaliação e acompanhamento psicológico. Essas demandas foram associadas à precarização da política pública, sobrecarga de trabalho às equipes e conflitos éticos às(aos) psicólogas(os). Como posicionamentos, é apontado que a(o) psicóloga(o) pode recusar as solicitações, conforme justificativa de impedimento ético e técnico, porém deve-se priorizar acatá-las, executando-as conforme as especificidades do SUAS, não excedendo sua competência. CONCLUSÃo: Concluiu-se que a psicologia no SUAS pode contribuir com o SJ a partir de uma atuação intersetorial que respeite os objetivos da Assistência Social. O papel mediador das gestões é fundamental para elucidar atribuições e estabelecer fluxos profícuos de trabalho.

PALAVRAS-CHAVE: Assistência Social. Sistema de Justiça. Psicologia. Políticas Públicas.
ABSTRACT | OBJECTIVE: This study is a documentary research that aimed to present a critical analysis of the relation between the Sistema Único de Assistência Social (SUAS) (Brazilian Social Service System) and the Brazilian Justice System (S), with a focus on psychology. METHOD: Eight official documents adopted by the Brazilian Psychology Councils System as a reference for guidance were analyzed. MAXQDA software support was used for analysis. We tried to answer three questions: (a) How does the relation between SUAS and SJ occur? (b) What are the impacts of the SJ's demands on the organization of the psychologist's work at SUAS? (c) What positions and orientations does the Brazilian Psychology Councils System take on this issue? RESULTS: It was found that the performance of psychology at SUAS in interface with the SJ involves planned activities, such as the execution of socioeducational measures and participation in hearings, but it is often affected by demands that go beyond planning, including carrying out a forensic evaluation, assessment, and psychological care. The demands that go beyond the objectives of SUAS were attributed to the precariousness of public policy, work overload for teams, and ethical conflicts for psychologists. As positions, it is pointed out that the psychologist may refuse requests, $f$ to the justification of ethical and technical impediment, but it must be prioritized to comply with them, executing them according to the specifics of SUAS, not exceeding its competence. CONCLUSION: It was concluded that psychology at SUAS could contribute to the SJ through intersectoral work that respects the objectives of Social Service. The mediating role of managers is fundamental to elucidate attributions and establish fruitful workflows.

KEYWORDS: Social Work. Justice system. Psychology. Public Policy. 


\section{Introdução}

Entende-se por Sistema de Justiça (SJ) o conjunto de órgãos vinculados aos Tribunais de Justiça, distribuídos por comarcas pelo território brasileiro, especialmente as Varas especializadas. Incluem-se também outros dispositivos, como instituições prisionais e de segurança pública, Defensoria Pública e Ministério Público (Sadek, 2010). Tais órgãos possuem, em essência, o objetivo de exercer funcionamento da garantia dos direitos e deveres estabelecidos pelos códigos legais. Na atuação em Políticas Públicas, é inerente a vinculação com tais códigos, já que sua instituição, regulamentação e administração são definidos por dispositivos formais pautados em leis, decretos e portarias. Assim, é recorrente o estabelecimento de relações, prescritas ou ocasionais, entre o SJ e os demais equipamentos públicos.

Este estudo toma como referência a Política pública de Assistência Social, executada pelo Sistema Único de Assistência Social (SUAS). O SUAS é um dos principais campos de atuação da psicologia no primeiro setor, apresentando uma extensa capilarização, estando presente em todos os municípios brasileiros e sendo responsável por grande parte da interiorização dessa profissão no país (Macedo \& Dimenstein, 2011). Nessa política, a interface com a justiça é constante e tem sido alvo de debates no campo profissional e acadêmico, envolvendo orientações específicas por parte do Conselho Federal de Psicologia (CFP).

O SUAS ganha peso legal pela Lei Orgânica de Assistência Social (LOAS) (Lei No 8.742, 1993), atualizada pela Lei $12.435 / 11$. Sua formulação foi respaldada pela Constituição Federal de 1988, na qual a assistência social compõe o tripé da seguridade social, junto à saúde e à previdência. Em 2004, foi aprovada a Política Nacional de Assistência Social (PNAS) (Resolução CNAS no 145, 2004), estruturando o SUAS, reforçando seus princípios e diretrizes que são reafirmados posteriormente pela Norma Operacional Básica do Sistema Único de Assistência Social - SUAS (NOB/SUAS 2012) (Resolução CNAS n 33, 2012).

O SUAS é um sistema público, descentralizado e não contributivo. Também possui caráter participativo, pois pressupõe o acato às decisões tomadas nos órgãos de controle social em âmbito municipal, estadual e nacional. Respaldado na LOAS, o SUAS apresenta por funções: a proteção social a famílias, crianças, idosos, dentre outros grupos vulneráveis; a vigilância socioassistencial; promoção e reintegração ao mercado de trabalho; e a defesa de direitos sociais. Através de serviços, benefícios, projetos e programas socioassistenciais, busca apoiar seus usuários no "enfrentamento de situações de vulnerabilidade, de risco pessoal e social, e violação de direitos" (Lei ${ }^{\circ}$ 8.742, 1993).

$\mathrm{Na}$ atuação em políticas públicas torna-se imprescindível compreender o contexto econômico, histórico e político no qual os usuários se encontram, no intuito de desenvolver ações coerentes com a conjuntura presente. A psicologia pode auxiliar na compreensão das subjetividades que se formam em imersão nesses contextos, delineando práticas pertinentes e realizando interpretações condizentes à práxis com os sujeitos reais, longe das abstrações que perduraram nos manuais técnicos. A atuação da psicologia no SUAS envolve a execução de ações voltadas ao fortalecimento de vínculos, superação das vulnerabilidades e valorização das potencialidades dos usuários, englobando essencialmente atividades comunitárias, mas sem deixar de exercer escutas e atendimentos individuais, ainda que esses atendimentos não devam reproduzir uma prática clínica psicoterapêutica (Duarte \& Aerosa, 2020).

Segundo a PNAS, detalhada no documento de Tipificação dos Serviços Socioassistenciais (Resolução CNAS n 109, 2009), o SUAS se organiza em dois níveis de proteção: Proteção Social Básica (PSB) e Proteção Social Especial (PSE). Cada nível de proteção compõe serviços e estratégias específicas para lidar com questões referentes à política, de acordo com sua complexidade e com as ações necessárias para enfrentar as situações relativas ao alcance do SUAS.

A PSB apresenta como objetivos a prevenção de riscos sociais e "destina-se à população que vive em situação de vulnerabilidade social decorrente da pobreza, privação e/ou fragilização de vínculos afetivos" (Resolução CNAS n 145,2004$)$. Essas situações podem ser decorrentes de inequidades relacionadas a questões de renda, gênero, geração, deficiência, dentre outras. As ações relacionadas à PSB são executadas principalmente pelos Centros de Referência em Assistência Social (CRAS), que serão responsáveis por alavancar projetos e programas socioassistenciais, bem como intermediar a concessão de benefícios. Os CRAS se articulam com outros serviços do SUAS, bem como de outras políticas públicas, no intuito de enfrentar a multicausalidade das situações de vulnerabilidade presentes na 
comunidade. Para tanto, devem possuir implementados o Programa de Atenção Integral à Família (PAIF) e o Serviço de Convivência e Fortalecimento de Vínculos (SCFV). Segundo o Conselho Federal de Psicologia (2008), o trabalho da psicologia nesse contexto consiste em participar de todas as ações dos Serviços, concessão de Benefícios e execução de Programas e Projetos do SUAS.

Diferente da PSB, cujo foco principal é prevenir a ocorrência de situações de risco e violações de direitos, a Proteção Social Especial (PSE) organiza estratégias e serviços para lidar com tais situações após seu acontecimento. Assim, casos de negligência, abandono, violências, dentre outros, são abarcados nesse nível de proteção. Os serviços, projetos e programas abarcados pela PSE seguem as diretrizes do SUAS e devem visar ao fortalecimento dos vínculos sociocomunitários e familiares, destacando a autonomia dos sujeitos e fortalecendo suas potencialidades. A PSE se subdivide em dois níveis de complexidade: alta complexidade e média complexidade, em ambos se pressupõe a presença de psicólogos como obrigatórios nas equipes multidisciplinares.

A Tipificação Nacional de Serviços Socioassistenciais (Resolução CNAS no 109, 2009) define que constituem unidades públicas para a oferta de serviços especializados da Proteção Social Especial de Média Complexidade: Centro de Referência Especializado de Assistência Social (CREAS); Centro de Referência Especializado para População em Situação de Rua (Centro Pop); e Centro-Dia. Nesses dispositivos ofertam-se os seguintes serviços: Serviço de Proteção e Atendimento a Famílias e Indivíduos (PAEFI); Serviço de Proteção Social a Adolescentes em Cumprimento de Medida Socioeducativa de Liberdade Assistida e de Prestação de Serviços à Comunidade; Serviço Especializado em Abordagem Social; Serviço de Proteção Social Especial para Pessoas com Deficiência, Idosos e suas Famílias; e Serviço Especializado para Pessoas em Situação de Rua.

Dos dispositivos destacados, ganha destaque o CREAS por conta da sua capilaridade dentro do território brasileiro. Na ausência dos demais, o CREAS fica responsável por executar os serviços da PSE no município, sempre em articulação com a rede de políticas públicas local.

O Ministério Público do Paraná (s.d.), em consonância com a Tipificação Nacional de Serviços
Socioassistenciais (Resolução CNAS n 109, 2009) define que constituem unidades públicas para a oferta de serviços especializados da Proteção Social Especial de Alta Complexidade aqueles que promovem "serviços especializados, em diferentes modalidades e equipamentos, com vistas a afiançar segurança de acolhida a indivíduos e/ou famílias afastados temporariamente do núcleo familiar e/ou comunitários de origem" (p. 2). Para a sua oferta, deve-se assegurar proteção integral aos sujeitos atendidos, garantindo atendimento personalizado e em pequenos grupos, com respeito às diversidades (ciclos de vida, arranjos familiares, raça/etnia, religião, gênero e orientação sexual). Tais serviços devem primar pela preservação, fortalecimento ou resgate da convivência familiar e comunitária - ou construção de novas referências, quando for o caso - adotando, para tanto, metodologias de atendimento e acompanhamento condizente com esta finalidade

Segundo o documento de tipificação (Resolução CNAS no 109, 2009), os serviços incluídos na PSE de Alta complexidade são: Serviço de Acolhimento Institucional; Serviço de Acolhimento em República; Serviço de Acolhimento em Família Acolhedora; Serviço de proteção em situações de calamidades públicas e de emergências. Há equipamentos de acoIhimento institucional destinados a crianças e adolescentes, mulheres em situação de violência, idosos, jovens e adultos com deficiência e adultos e família. O acolhimento deve ter caráter provisório e excepcional e funcionar em espaços residenciais não destoantes da comunidade, buscando-se ao máximo integrar as instituições aos recursos do território.

Destaca-se que a psicologia se insere em todos os níveis de proteção social apresentados. Por ser uma política nova, considerando a organização atual, ainda há desafios teóricos e metodológicos que sustentem um fazer da psicologia alinhado ao campo da assistência social. Gomes e Gonçalves (2018) apontam que, para além da novidade do campo, o trabalho no SUAS põe em cheque "tradições" da psicologia: uma área socialmente percebida como voltada para a elite, executada em atendimentos individuais e pautada na realização de diagnósticos. Outra problemática se refere ao trânsito da psicologia com outras políticas públicas e, no caso do SJ, a pouca ocorrência de profissionais concursados. Desse modo, são comuns demandas advindas dos órgãos de justiça para psicólogas(os) da assistência social, mais comumente disponíveis principalmente em municípios de pequeno porte. 
No ano de 2015 foi lançado o maior estudo, até então, sobre as relações entre o SUAS e o SJ, em pesquisa que envolveu o Ministério da Justiça e o Instituto de Pesquisa Econômica Aplicada (Ministério da Justiça, 2015). Esse documento apresenta uma realidade nacionalizada e reafirma a especificidade da Assistência Social, sendo esta frequentemente ignorada perante as requisições do SJ. Segundo a pesquisa, são frequentes requisições de perícias, averiguações de denúncias, atendimentos diretos em serviços específicos (vagas para instituições de acolhimento, programas e cadastros de benefícios eventuais), e solicitações sobre informações acerca de atendimentos realizados nos equipamentos do SUAS.

As requisições partem principalmente dos juízes, Ministério Público e Defensoria, e buscam serviços individualizados, como atendimento psicoterápico e avaliações psicodiagnósticas, se contrapondo à atuação sociofamiliar que orienta a prática na Assistência Social, que pressupõe atividades de âmbito familiar e comunitário, ainda que os atendimentos individuais não-clínicos sejam parte do instrumental. Tal debate foi abordado por Cordeiro e Curado (2017), que criticam o fazer psicológico pautado no modelo clínico dentro do SUAS, a despeito das orientações contrárias do Conselho Federal de Psicologia e órgãos regulatórios da Assistência Social. Para as autoras, mesmo que o método psicoterápico não seja praticado, por vezes profissionais acabam enquadrando demandas socioassistenciais a partir de perspectivas que encerram no sujeito a causa última de problemáticas de ordem social. Isso colabora com uma visão restrita internamente e externamente ao SUAS quanto ao trabalho da psicologia nos dispositivos da assistência social, sendo atraídas cada vez mais solicitações que implicam em práticas apartadas da intervenção social, familiar e comunitária.

Diante desse cenário, o Ministério da Justiça (2015) apresenta propostas de alinhamento entre os objetivos do SUAS e as demandas do SJ, como: (a) definição de fluxos precisos de interlocução, respeitando as normativas vigentes; (b) instituição de comissões intergestores que ampliem o diálogo entre as gestões dos dois sistemas; (c) realização de audiências concentradas que tematizem o SUAS, dentre outras ações que fortaleçam uma atuação intersetorial sem ferir as competências de cada campo. Questiona-se, neste estudo, se essas orientações foram incorporadas pela relação entre o SUAS e o SJ, e se tais precauções têm guiado o trabalho de psicólogas(os) inseridas(os) na política pública de Assistência Social.

Este artigo tem por objetivo tecer uma análise crítica sobre a relação entre o Sistema Único de Assistência Social e o Sistema de Justiça brasileiro, com foco na atuação da psicologia inserida nos dispositivos socioassistenciais. Busca-se delinear as principais demandas relacionadas ao tema, partindo de um estudo documental, tomando como base os documentos orientadores produzidos e/ou amplamente adotados pelo Conselho Federal de Psicologia e Conselhos Regionais de Psicologia. Deste modo, espera-se que este artigo sirva de base para orientar reflexões de profissionais do SUAS, bem como operadores do Direito, ao expor as particularidades de cada atuação e o panorama orientador que pauta o trabalho da psicologia na Assistência Social.

\section{Método}

Trata-se de um estudo teórico e documental descritivo, de base qualitativa, que busca, a partir de documentos oficiais do Sistema Conselhos de Psicologia', tecer uma análise crítica sobre a interface entre a atuação da psicologia no SUAS e as demandas relacionadas ao SJ. A escolha dos documentos a serem analisados partiu da experiência do pesquisador, que possui proximidade com um dos Conselhos Regionais de Psicologia e amplo contato com normativas e documentos orientadores. Excepcionalmente, o documento intitulado "Relação entre o Sistema Único de Assistência Social - SUAS e os órgãos do Sistema de Justiça" foi incluído, mesmo sendo oriundo do então Ministério do Desenvolvimento Social e Combate à Pobreza (MDS), devido a seu potencial de referência e ampla utilização em processos orientadores do Sistema Conselhos de Psicologia. O Quadro 1 apresenta os documentos analisados.

${ }^{1}$ A nomenclatura Sistema Conselhos de Psicologia engloba o Conselho Federal de Psicologia e todo o conjunto de Conselhos Regionais de Psicologia. 
Quadro 1. Documentos oficiais que abordam a relação entre SUAS e Sistema de Justiça

\begin{tabular}{|l|l|l|}
\hline Ano & Documento & Origem \\
\hline 2008 & Referências Técnicas para atuação do(a) psicólogo(a) no CRAS/SUAS & CFP/CREPOP \\
\hline 2011 & $\begin{array}{l}\text { Como os Psicólogos e as Psicólogas podem Contribuir para Avançar o } \\
\text { Sistema Único de Assistência Social (SUAS) - Informações para Gestoras e } \\
\text { Gestores }\end{array}$ & CFP/CREPOP \\
\hline 2012 & $\begin{array}{l}\text { Referências Técnicas para Atuação das Psicólogas em Programas de } \\
\text { Medidas Socioeducativas em Meio Aberto }\end{array}$ & CFP/CREPOP \\
\hline 2013 & $\begin{array}{l}\text { Referências Técnicas sobre a Prática de Psicólogas(os) no Centro de } \\
\text { Referência Especializado da Assistência Social (CREAS) }\end{array}$ & CFP/CREPOP \\
\hline 2015 & $\begin{array}{l}\text { Parecer a Respeito de Pedido Oriundos do Ministério Público e do Poder } \\
\text { Judiciário aos Profissionais das políticas públicas de Assistência Social e } \\
\text { de Saúde - orientações e reflexões }\end{array}$ & $\begin{array}{l}\text { Conselho Regional de } \\
\text { Psicologia 11 } 11^{\text {Região }} \\
\text { (CRP-11) }\end{array}$ \\
\hline 2016 & $\begin{array}{l}\text { Relação entre o Sistema Único de Assistência Social - SUAS e os órgãos } \\
\text { do Sistema de Justiça }\end{array}$ & SNAS/MDS \\
\hline 2016 & $\begin{array}{l}\text { Demandas do Sistema de Justiça às(aos) Profissionais de Psicologia } \\
\text { Lotados nas Políticas Públicas de Saúde e de Assistência Social }\end{array}$ & CFP/CONPAS \\
\hline 2016 & $\begin{array}{l}\text { Orientações sobre documentos elaborados por psicólogas e psicólogos } \\
\text { no âmbito do Sistema Único de Assistência Social (SUAS) }\end{array}$ & CFP/CONPAS \\
\hline
\end{tabular}

Fonte: O autor (2021).

Buscou-se responder, ao longo da análise, as seguintes questões: (a) Como ocorre a relação entre o SUAS e o SJ? (b) Quais os impactos das demandas do sistema de justiça na organização do trabalho da(o) psicóloga(o) no SUAS? (c) Quais posicionamentos e orientações o Sistema Conselhos de Psicologia adota perante essa questão? Cada questionamento apresentado foi transformado em uma categoria principal.

Os elementos que compuseram essas categorias foram formulados a partir da estratégia de codificação aberta, oriunda da Teoria Fundamentada nos Dados. Nesse processo, foi realizada uma leitura integral dos documentos, dando destaque aos segmentos de texto que evidenciassem a temática de interesse. Na codificação aberta, palavras e ideias que se comunicassem com os questionamentos elencados foram previamente selecionados e, posteriormente, foi relido o contexto em que se encontravam. Essa releitura permitiu refinar a categorização. Para tanto, segiu-se a orientação de Gasque (2007), segundo o qual, para que o processo de codificação aberta seja eficaz, ao encarar os dados o pesquisador deve indagar "o que é isso?" e "o que isso representa"? Seguindo essas orientações, foram formadas as subcategorias expressas nos Quadros 2, 3 e 4.

A análise dos documentos foi realizada com auxílio do software de análises qualitativas MAXQDA. Foram utilizados os recursos de codificação, análise de segmentos, nuvens de palavras, visualizador de matriz de códigos e MAXMaps, uma ferramenta visual que permite observar dinamicamente a conexão entre documentos, categorias formuladas e segmentos codificados.

\section{Resultados e discussões}

\section{Características da relação entre o Sistema Único de Assistência Social e o Sistema de Justiça}

Os documentos demonstraram que a relação entre o SUAS e o SJ podem ocorrer em duas principais configurações. Na primeira, encontram-se atividades pré-estabelecidas na política pública de Assistência Social que envolvem a ação das equipes do SUAS em interface com os dispositivos do SJ. Na segunda, localizam-se as atividades demandadas pelo SJ que fogem ao escopo previsto nos planos de trabalho das equipes do SUAS. 
Constatou-se que a relação prevista entre o SUAS e o SJ ocorre em todos os níveis de complexidade da Assistência Social. A análise dessa articulação na Proteção Social Básica demanda a compreensão do público e objetivos do SUAS. A PNAS (2004) apresenta como público usuário da Assistência Social todos os cidadãos e grupos que se encontram em situações de vulnerabilidade e riscos, incluindo: famílias e indivíduos com perda ou fragilidade de vínculos; ciclos de vida (crianças, adolescentes, idosos); identidades estigmatizadas em termos étnico, cultural e sexual; pessoas com deficiência; pessoas em situação de pobreza; pessoas inseridas precariamente no mercado de trabalho; usuários abusivos de substâncias psicoativas, dentre outras condições. Assim, mesmo os serviços que não foram apontados como formalmente relacionados com a justiça lidam cotidianamente com populações com demandas amparadas legalmente, ou que têm a possibilidade de uma inserção em processos judiciais diante das consequências da fragilidade social, que pode se materializar, por exemplo, em situações de exclusão, violências ou outras formas de opressão.

Nesse sentido, mesmo que o Documento de Referência Técnica para atuação do(a) psicólogo(a) no CRAS/SUAS (CFP, 2008) não evidencie uma atuação em interface com o SJ, este reafirma uma atuação da psicologia na efetivação de direitos sociais. Assim, o CRAS pode ser encarado também como um instrumento de prevenção da judicialização desses casos, na medida em que promove ações de fortalecimento social, ampliação da autonomia e prevenção de situações de risco e vulnerabilidades. Destaca-se que, além de significar um agravamento da situação de vulnerabilidade, a judicialização das demandas socioassistenciais pode ter efeitos adversos no vínculo estabelecido entre as equipes do SUAS e as famílias, diante da inclusão do SJ nessa mediação (Saramento et al., 2019).

Na Proteção Social Especial, essa articulação entre o SUAS e o SJ fica mais evidente. A alta complexidade lida com públicos cuja institucionalização se torna recurso. Situações de violência, negligência, abusos, tráfico de pessoas, dentre outras violações, necessariamente passam por processos de judicialização (CFP, 2008, 2016a, 2016b). A exemplo da institucionalização de crianças e adolescentes em abrigos, casas-lares, ou mesmo nas famílias acolhedoras, cabe ao judiciário dar aval para ações das equipes multidisciplinares, e definir o direcionamento dos usuários (como a destituição do poder familiar, ou o encaminhamento para alguma família substituta). Todo esse processo ocorre assessorado pelas equipes da Assistência Social, através da elaboração de relatórios periódicos, e contatos frequentes com o SJ para estudos de caso e participação em audiências.

Também na Proteção Social Especial, merece destaque a atuação dos CREAS, dispositivos que executam funções intimamente relacionadas com as demandas da justiça, o que se materializa na definição da equipe mínima dessa instituição, que envolve a presença de psicóloga(o), assistente social e advogada(o) (CFP, 2013). Ademais, os CREAS são dispositivos que executam, de modo prioritário, as Medidas Socioeducativas de Meio Aberto: Prestação de Serviços à Comunidade (PSC) e Liberdade Assistida (LA).

A atuação da psicologia no SUAS perante a execução das Medidas Socioeducativas de Meio Aberto é uma das principais atividades que denotam a interseção com o SJ (CFP, 2012, 2013). Essas medidas são regidas pelo Estatuto da Criança e do Adolescente (Lei ${ }^{\circ}$ $8.069,1990$ ) e pelo Sistema Nacional de Atendimento Socioeducativo (Sinase) (Lei $n^{\circ} 12.594,2012$ ), sendo aplicadas por determinação judicial a adolescentes que infringiram a lei. O cumprimento das Medidas Socioeducativas de Meio Aberto ocorre com o adolescente em comunidade, sendo acompanhado por equipe multidisciplinar. Dessa forma, a psicologia é demandada a realizar acompanhamento em casos de aplicação de PSC e LA, devendo elaborar um Plano Individual de Atendimento (PIA) com o adolescente e família, documento que estabelece metas, intermediando as ações socioeducativas no SUAS com o SJ. Esse intermédio ocorre por meio da emissão de documentos, contatos diretos, estudos de caso e participação em audiências judiciais.

A articulação com a rede intersetorial é outro ponto característico da atuação. Os documentos reafirmam que o SUAS faz parte de uma rede que envolve os sistemas de saúde, educação, justiça, previdência, dentre outros âmbitos das políticas públicas. Precisamente com o SJ, é pontuada a interseção feita diretamente entre as(os) psicólogas(os) do SUAS e com o judiciário através de contatos, audiências e estudos de caso (CFP, 2012, 2013, 2016a, 2016b). Nesse aspecto, há dificuldades apontadas, como: "a burocracia dos encaminhamentos, a desarticulação da rede, a morosidade do judiciário, a precariedade dos Conselhos Tutelares, entre outros" (CFP, 2013, p. 
39). Do mesmo modo, salienta-se a importância da não redução da articulação com a rede intersetorial a um simples processo de encaminhamentos, que se resume à transmissão de responsabilidades. Deve-se, por outro lado, estabelecer objetivos compartilhados relacionados a cada caso, respeitando a atribuição de cada política pública envolvida (Romagnoli \& Silva, 2019).

Como observado, a relação entre o SUAS e o SJ pode fazer parte do escopo dos dispositivos socioassistenciais. Entretanto, observa-se uma problemática quando essas demandas passam a ser a centralidade dos serviços, ou quando extrapolam a função das equipes nesse contexto. O Conselho Federal de Psicologia (2016a, 2016b), o Ministério do Desenvolvimento Social e Combate à Pobreza (2016), e o Conselho Regional Psicologia da $11^{\text {a }}$ Região (2015) apontam que, para além das atividades apresentadas, as requisições do SJ aos dispositivos do SUAS envolvem: acompanhamento psicológico, avaliação psicológica ou social, e averiguação de denúncias. Os documentos revelam que essas demandas podem gerar problemáticas e comprometer o cumprimento dos objetivos do SUAS. Aspectos relacionados às solicitações e encaminhamentos oriundos do SJ têm sido debatidos amplamente na área do Serviço Social (Saramento, 2018; Pereira \& Zaniani, 2019), mas, embora ocupe parte da agenda do Sistema Conselhos de Psicologia, pouco têm sido explorados nas produções científicas em Psicologia.

O Quadro 2 apresenta, de modo sistematizado, as atividades executadas pela(o) psicóloga(o) do SUAS em interface com o SJ, com base nos documentos analisados.

Quadro 2. Atividades da psicologia no SUAS em interface com o SJ

\begin{tabular}{|l|l|}
\hline Atividade & Documento em que consta \\
\hline Acompanhamento psicológico & CFP $(2016 \mathrm{a}, 2016 \mathrm{~b}) ;$ MDS (2016); CRP-11 (2015) \\
\hline Articulação intersetorial & CFP $(2012,2013,2016 \mathrm{a}, 2016 \mathrm{~b}) ;$ MDS (2016); CRP-11 (2015) \\
\hline Avaliação psicológica & CFP $(2016 \mathrm{a}, 2016 \mathrm{~b})$ \\
\hline Averiguação de denúncias & CFP $(2016 \mathrm{a})$ \\
\hline Elaboração de documentos & CFP $(2012 ; 2013,2016 \mathrm{a}, 2016 \mathrm{~b}) ;$ MDS (2016); CRP-11 (2015) \\
\hline Encaminhamentos & CFP $(2012,2013) ;$ MDS (2016) \\
\hline Orientação jurídico-social & CFP $(2013)$ \\
\hline Participação em audiências & CFP $(2012,2013,2016 a, 2016 \mathrm{~b}) ;$ CRP-11 (2015) \\
\hline Prevenção de violações de direitos & CFP $(2008,2016 \mathrm{a}, 2016 \mathrm{~b})$ \\
\hline
\end{tabular}

Fonte: O autor (2021).

As formas de atuação apresentadas envolvem a ação da psicologia nos serviços socioassistenciais em interface com o SJ. É importante pontuar que essa prática não é uma reprodução da psicologia jurídica executada nos tribunais, Ministério Público, Defensoria Pública e afins, que se reverbera nas atividades das(os) psicólogas(os) do SUAS. As(os) profissionais do SUAS são orientados por diretrizes setoriais condizentes com a PNAS e se pautam nos modos de trabalho e objetivos específicos da Assistência Social.

\section{Impactos das demandas do sistema de justiça na organização do trabalho da(o) psicóloga(o) no SUAS}

Segundo os documentos analisados, respeitados os fluxos e as especificidades do SUAS, as ações previstas de interlocução com o SJ são vantajosas à população usuária. A atuação interdisciplinar e intersetorial é prerrogativa do SUAS e, de fato, em diversas situações é necessário estabelecer relações com a justiça, de modo a garantir os direitos sociais à população atendida nos dispositivos socioassistenciais.

Observou-se, entretanto, que a maior preocupação expressa nos documentos sobre esse quesito se refere ao impacto das requisições do SJ aos dispositivos do SUAS que não compreendem o fluxo previsto de atuação, e/ ou são apresentadas de modo coercitivo e pouco alinhado com a política pública de Assistência Social. A falta de interpretação de outros setores sobre a atuação do SUAS é referenciado pelo Conselho Federal de Psicologia (2012). Esse processo gera impactos diretos no trabalho das(os) psicólogas(os) e no SUAS, reverberando em equipes e usuários. 
As demandas do SJ foram associadas amplamente à precarização do SUAS (CFP, 2016a, 2016b; MDS, 2016). Isso se dá pela inadequação das solicitações da justiça em relação aos objetivos da Assistência Social. Essa inadequação reduz o tempo efetivo da prática socioassistencial, dificultando a atenção aos usuários do SUAS (CFP, 2016a, 2016b). Pontua-se também que os prazos para execução das demandas do SJ são condicionados ao fluxo da justiça, atrapaIhando os planejamentos dos dispositivos do SUAS, que operam em ritmo próprio (CFP, 2013).

Um ponto que se refere especialmente a atuação da psicologia é a dificuldade nas definições de papéis. $\mathrm{A}(\mathrm{O})$ psicóloga(o) que atua na Assistência Social ainda demanda reafirmar uma prática diferente dos modelos clínicos que predominaram no fazer dessa profissão ao longo de seu desenvolvimento no Brasil. As requisições da justiça por práticas não condizentes com as técnicas adequadas aos objetivos do SUAS obnubila o papel da psicologia nesses espaços, enfraquecendo sua contribuição (CFP, 2013).

O prejuízo na qualidade do trabalho da psicologia no SUAS diante das demandas do SJ também foi abordado. Os documentos apontam que o tipo de vínculo estabelecido no exercício de uma perícia é distinto daquele previsto para a(o) profissional que assiste às famílias nos dispositivos socioassistenciais. Desse modo, contrapor o trabalho social com famílias com atividades periciais e avaliativas pode acarretar conflitos éticos graves (CFP, 2016a, 2016b; MDS, 2016; CRP11, 2015). Incluem-se, nesse quesito, preocupações quanto a: sigilo, guarda de material e estabelecimento de relações que podem comprometer a execução das tarefas. Ademais, é comum que requisições da justiça sejam realizadas a psicólogas(os) alocadas(os) em CRAS e CREAS de municípios pequenos, sendo muitas vezes as(os) únicas(os) profissionais de psicologia em serviços públicos nesses territórios. Assim, a possibilidade desta(e) profissional estar realizando alguma atividade de cunho socioassistencial com algum usuário jurisdicionado existe, e assumir o papel de perita(o) ou qualquer outro demandado pelo SJ pode invalidar outras vias de atuação, comprometendo o trabalho no SUAS.

Os documentos apontam também a diferença dos objetivos e dos posicionamentos do SUAS e do SJ perante as demandas trabalhadas pela psicologia, gerando conflitos que pode aviltar o serviço executado. Ressalvadas as situações contrárias, o Conselho Federal de Psicologia (2012; 2013) evidencia essa divergência no que tange ao trabalho com Medidas Socioeducativas, no qual o SJ ressalta frequentemente um viés punitivista, enquanto as equipes socioassistenciais devem se ater ao princípio educativo, de modo a cumprir os demais objetivos da socioeducação.

Outro impacto relevante se refere aos danos à saúde do trabalhador. Os documentos pontuam que a sobrecarga de trabalho proveniente das ações previstas no SUAS acrescidas das demandas do SJ tem gerado sofrimento laboral às(aos) psicólogas(os) (CRP-11, 2015; CFP, 2016a). Outrossim, o abuso de poder partindo dos operadores da justiça para com as equipes do SUAS foi pontuado como um problema recorrente, gerando situações de trabalho patogênicas que implicam diretamente na efetividade e na qualidade do serviço realizado (CRP-11, 2015; CFP, 2013, 2016a).

O Quadro 3 apresenta, de modo sistematizado, os principais impactos das demandas do SJ ao SUAS ilustrados pelos documentos analisados. Foram incluídos impactos diretamente voltados à atuação das(os) profissionais de psicologia, mas também aqueles relacionados à política pública de Assistência Social de modo mais amplo, assumindo sua reverberação nas equipes que a executam. 
Quadro 3. Impactos apontados das demandas do SJ no trabalho de psicólogas(os) do SUAS

\begin{tabular}{|l|l|}
\hline Impacto & Documento em que consta \\
\hline Sobrecarga e sofrimento laboral & CRP-11 (2015); CFP (2016a); \\
\hline Precarização da política pública de Assistência Social & CFP (2016a, 2016b); MDS (2016). \\
\hline $\begin{array}{l}\text { Desvio de função por extrapolação de competências do } \\
\text { profissional e/ou do serviço, trazendo precarização na } \\
\text { qualidade do serviço prestado }\end{array}$ & $\begin{array}{l}\text { CFP (2016a, 2016b); MDS (2016); CRP-11 } \\
(2015)\end{array}$ \\
\hline Conflitos éticos & $\begin{array}{l}\text { CFP (2013, 2016a, 2016b); MDS (2016); CRP-11 } \\
(2015)\end{array}$ \\
\hline Conflito de posicionamentos & CFP (2012, 2013) \\
\hline Abuso de poder & CRP-11 (2015); CFP (2013, 2016a) \\
\hline
\end{tabular}

Fonte: O autor (2021).

Foi possível constar que a principal problemática apresentada nos documentos analisados se refere às solicitações do SJ às equipes do SUAS de realização de atividades não previstas na política pública de Assistência Social. Demandas que excedem as funções da psicologia no SUAS acabam por prejudicar os fluxos já estabelecidos conforme alinhados pela PNAS e planejamentos municipais e estaduais, impactando na qualidade do serviço ofertado e violando, por consequência, os direitos à população usuária. Por outro lado, os documentos respaldam que há atividades prevista que se pautam nessa interrelação e representam o compromisso de realizar o acompanhamento socioassistencial aos sujeitos abarcados por demandas judicializadas, contanto que não sejam feridos os objetivos da Assistência Social.

\section{Posicionamentos e orientações do Sistema Conselhos de Psicologia perante demandas do Sistema de Justiça no Sistema Único de Assistência Social}

A análise dos documentos torna evidente que as relações entre o SUAS e o SJ apresentam uma importante dimensão para o trabalho da psicologia. O modo como essa relação se estabelece acaba gerando um campo crítico de orientação por parte do CFP e demais instâncias do Sistema Conselhos de Psicologia. Alguns posicionamentos são explicitados acerca dessa interseção, sinalizando ações que as(os) psicólogas(os) do SUAS podem tomar perante impasses das requisições do SJ. Duas possibilidades centrais são apresentadas: a recusa e o atendimento às requisições.

A recusa não se refere à ausência de resposta, já que existe a determinação legal de obrigatoriedade de atendimento às requisições judiciais. Os documentos apontam para a possibilidade de recusa justificada, na qual a(o) profissional e a gestão do SUAS (do serviço ou do município) sinalizam a impossibilidade de execução da tarefa demandada diante de conflito de competência do serviço, barreiras éticas e técnicas, ou qualquer outro fator que impeça tal atividade.

As razões para a recusa são geralmente amparadas no Código de Ética Profissional do Psicólogo (CEPP), que sinaliza o dever de o profissional aceitar apenas trabalhos para os quais se sinta tecnicamente e pessoalmente capacitado (CRP-11, 2015; CFP, 2016a). O CEPP salienta também a impossibilidade de realização de atividades não havendo condições estruturais adequadas. Tal aspecto torna-se evidente quando há demandas de psicodiagnóstico, as quais são executadas frequentemente com apoio de instrumentos de avaliação psicológica que não fazem parte do escopo do SUAS e, em geral, não estão disponíveis nos dispositivos socioassistenciais. Ademais, o Conselho Federal de Psicologia (2016b) reitera que o trabalho da psicologia não pode ser generalizado ao extremo, havendo especialidades que devem ser respeitadas. Nesse sentido, reforça que o escopo da psicologia jurídica não se enquadra nos fazeres da Assistência Social. 
Acrescenta-se, como razões de recusa: a não realização de procedimentos psicológicos com intuito de gerar provas, a dificuldade em manter sigilo de informações coletadas nos processos periciais em alguns cenários de atuação no SUAS, e a quebra de vínculo proveniente do trabalho demandado pelo $S$ J, dificultando as atividades de cunho socioassistencial. Em situações de insistência do SJ após recusa fundamentada pela(o) psicóloga(o), sugere-se a notificação à gestão do serviço e ao Conselho Regional de Psicologia responsável, adiantando o possível acometimento de infração perante requisição judicial (CRP-11, 2015).

Os documentos sinalizam que toda comunicação de devolutiva ao SJ, incluindo a recusa, deverá ter caráter educativo, auxiliando a rede na elucidação dos objetivos do SUAS e da especificidade do trabalho da(o) psicóloga(o) nessa política (CRP-11, 2015; CFP, 2016a, 2016b). A participação da(o) profissional de psicologia em espaços de controle social, fóruns interinstitucionais, rodas de conversa e outros contextos de discussão também é apontada como ferramenta. Os documentos analisados ressaltam que essas ações tendem a fortalecer o diálogo entre os sistemas e alinhar melhor as demandas, reafirmando o respeito e colaboração entre as equipes da rede intersetorial (CFP, 2012, 2013; MDS, 2016; CRP-11, 2015).

No atendimento às demandas do $\mathrm{S}$, os documentos analisados sinalizam a necessidade de obedecer aos princípios do SUAS, à especificidade da atuação da psicologia nesse contexto, e às deliberações éticas da categoria. Deve-se também observar as legislações vigentes, garantindo que $\mathrm{a}(\mathrm{o})$ profissional não descumpra as normativas que orientam sua atuação.

Assim, torna-se inviável, por exemplo, a elaboração de laudos periciais e outros documentos provenientes de avaliação psicológica, por não fazerem parte do escopo da política pública de Assistência Social. Em demandas de avaliação, a(o) psicóloga(o) deve acolher o usuário jurisdicionado e inseri-lo nos serviços do SUAS, sendo os documentos elaborados e compartilhados com o SJ condizentes com essa atuação (CFP 2012, 2013, 2016a, 2016b). As demandas deverão ser problematizadas no documento, evidenciando o viés crítico de análise da realidade social e histórica em que o usuário se encontra, evitando encerrá-lo em uma faceta jurídica em detrimento da sua inserção sociocomunitária (CRP-11, 2015).
O Conselho Federal de Psicologia (2016a) levantou o direcionamento das requisições, sendo a maior parte (61\%) enviada aos órgãos gestores (prefeituras, secretaria, coordenação, etc.), e um quantitativo significativo (18\%) diretamente aos profissionais. Diante disso, a necessidade de discussão das problemáticas aqui descritas entre as instâncias gestoras é apontada na maior parte dos documentos analisados (CRP-11, 2015; CFP, 2012, 2013, 2016a, 2016b; MDS, 2016). Os documentos sinalizam a importância de fortalecer a atuação das gestões, ampliando o diálogo e evitando uma atuação intercruzada sem respeito às especificidades dos serviços. As gestões do SUAS devem assumir posicionamentos de garantia da execução da política pública de Assistência Social e respaldo às equipes técnicas. Entende-se, com isso, que a resposta imediata ao $\mathrm{SJ}$ deverá ser apresentada pela gestão do SUAS, protegendo a(o) profissional de psicologia de eventuais conflitos judiciais. Ademais, é a gestão que deverá zelar pelo cumprimento dos objetivos de cada serviço, evitando desvios que prejudiquem seu plano de atividades.

Cabe às gestões do SUAS, em diálogo com o SJ, estabelecer fluxos precisos, elucidando as possibilidades de atuação dos dispositivos socioassistenciais perante as demandas da justiça e englobando a rede intersetorial (CFP, 2016a; CRP-11, 2015; MDS, 2016). A precisão nos fluxos evita que atividades extraordinárias sejam demandadas e situa as equipes em um fazer alinhado aos princípios da política pública em que se inserem. O Ministério da Justiça (2015) corrobora esse posicionamento, reiterando que todo o trabalho das equipes multiprofissionais deverá ser orientado pelas gestões e o estabelecimento de fluxos adequados para a realização dessa atuação é imprescindível.

É importante pontuar que, apesar da implicação das gestões ser amplamente debatida nos documentos, aquele que aborda especificamente essa questão não menciona diretamente a importância do diálogo entre gestores do SUAS e instâncias do SJ de modo a alinhar a atuação da(o) psicóloga(o) da Assistência Social perante as demandas judiciais (CFP, 2011).

Por fim, os documentos reforçam que a(o) psicóloga(o) deverá estar ciente das situações de notificação compulsória, não sendo possível recusar essa execução, ainda que a demanda pareça extrapolar o trabaIho prescrito (CFP, 2016a; CRP-11, 2015). O Quadro 4 sintetiza os posicionamentos de orientação às(aos) profissionais de psicologia coletados nos documentos analisados. 
Quadro 4. Possibilidades à(ao) profissional de psicologia do SUAS perante demanda do SJ

\begin{tabular}{|l|l|}
\hline Atividade & Documento em que consta \\
\hline Diálogo envolvendo as gestões & CFP (2016a); MDS (2016); CRP-11 (2015) \\
\hline $\begin{array}{l}\text { Elaboração de documento ou proposta de atuação conforme } \\
\text { normativas do SUAS }\end{array}$ & CFP (2012, 2013, 2016a, 2016b) \\
\hline $\begin{array}{l}\text { Participação da(o) profissional em espaços de discussão e } \\
\text { controle social }\end{array}$ & CFP (2012, 2013); MDS (2016); CRP-11 (2015) \\
\hline Recusa & $\begin{array}{l}\text { Conselho Federal de Psicologia (2016a, } \\
\text { 2016b); CRP-11 (2015) }\end{array}$ \\
\hline
\end{tabular}

Fonte: O autor (2021).

\section{Considerações Finais}

Considera-se aqui que foi atingido o objetivo geral de tecer uma análise crítica sobre a relação entre o Sistema Único de Assistência Social e o Sistema de Justiça brasileiro, com ênfase na atuação da psicologia. A pesquisa documental realizada permitiu descrever essa interrelação de modo oficialmente dado e elucidar em quais pressupostos o Conselho Federal de Psicologia se baseia para delinear orientações sobre esse processo, possibilitando uma análise crítica sobre as informações expressas.

Dos documentos analisados, quatro são provenientes de pesquisas de campo, tendo ouvido profissionais de psicologia que atuam diretamente no SUAS, de modo a conhecer aprofundadamente os desafios vivenciados (CFP, 2008, 2012, 2013, 2016a). Todos os documentos se baseiam no Código de Ética Profissional do Psicólogo e nas demais resoluções do CFP para as análises realizadas, reforçando um caráter técnico e ético de referência para a categoria profissional.

A imersão nesses textos permitiu concluir que as(os) profissionais de psicologia alocadas(os) no SUAS têm a contribuir com o SJ, contanto que seja respeitada a especificidade da atuação nos dispositivos socioassistenciais, o que envolve a não execução de funções que excedam os objetivos da política pública de Assistência Social. Desse modo, a psicologia ocupa um papel não reduzido ao de ferramenta da justiça, na função de perícia e averiguação, mas centra-se na busca de garantia de direitos sociais atribuídos aos usuários da Assistência Social e de quem dela necessitar, orientada ao trabalho social com famílias e comunidades.

Os documentos analisados apresentam uma crítica acerca da pouca disponibilidade de peritos alocados nos Tribunais de Justiça. Essa falta impulsiona as solicitações de perícia partindo do SJ para profissionais das demais políticas públicas. Salienta-se que ao acatar essas demandas, oculta-se a falta de profissionais de psicologia jurídica devidamente concursadas(os) e sobrecarrega-se o trabalho de outras políticas públicas que sofrem mais com o subfinanciamento do que os órgãos de justiça (CFP, 2012; 2016a; CRP-11, 2015; MDS, 2016).

Conclui-se que as demandas do SJ às equipes do SUAS são ancoradas em um desconhecimento da especificidade da atuação desta política pública e podem gerar efeitos negativos como precarização e violação de direitos aos usuários. Especificamente a psicologia se encontra atravessada por um rigor ético a ser seguido, no qual se inclui o sigilo profissional, o exercício de atividades em ambiente adequado e o estabelecimento de relações que não impeçam a realização das intervenções. Os documentos sugerem que antes de acatar as demandas judiciais, as(os) psicólogas(os) avaliem se a atividade implicará em conflito ético.

Incentiva-se o diálogo constante com as equipes e entre profissionais da rede intersetorial. Os documentos avaliam que conforme as(os) profissionais do SUAS elucidem as demais políticas públicas acerca do papel da Assistência Social, o qual envolve o fortalecimento de vínculos sociais e comunitários e intervenções de combate a situações de vulnerabilidade e violação de direitos, menores serão as demandas que extrapolem seus objetivos. Nesse sentido, a função das gestões emerge como fundamental, formulando espaços de discussão e estabelecendo fluxos entre o executivo e judiciário envolvendo atividades condizentes com cada atribuição. 
Apesar de permitir uma investigação precisa de posicionamentos oficiais, o método de pesquisa documental possui evidentes limitações. Este estudo enfatizou uma prática profissional que não pode ser fielmente capturada pelos documentos selecionados, ainda que estes tenham sido oriundos de discussões com trabalhadoras(es) da ponta. Desse modo, no intuito de melhor qualificar as análises aqui apresentadas, sugere-se a realização de estudos com outras linhas metodológicas, preferencialmente empíricas, as quais podem acessar de modo mais aprofundado e prático o objeto alvo desta pesquisa.

\section{Conflitos de interesses}

Nenhum conflito financeiro, legal ou político envolvendo terceiros (governo, empresas e fundações privadas, etc.) foi declarado para nenhum aspecto do trabalho submetido (incluindo, mas não se limitando a subvenções e financiamentos, participação em conselho consultivo, desenho de estudo, preparação de manuscrito, análise estatística, etc.).

\section{Referências}

Conselho Federal de Psicologia. (2008). Referências Técnicas para atuação do(a) psicólogo(a) no CRAS/SUAS. CFP. https:// www.crpsp.org/uploads/impresso/230//80DpMPzHm0zhTdJZwqbm6RenlmAOr1.pdf

Conselho Federal de Psicologia. (2011). Como os Psicólogos e as Psicólogas podem Contribuir para Avançar o Sistema Único de Assistência Social (SUAS) - Informações para Gestoras e Gestores. CFP. https://site.cfp.org.br/wp-content/ uploads/2011/12/GestoresSuasfinal.pdf

Conselho Federal de Psicologia. (2012). Referências Técnicas para Atuação das Psicólogas em Programas de Medidas Socioeducativas em Meio Aberto. CFP. http://crepop.pol.org. br/wp-content/uploads/2012/10/Atua\%C3\%A7\%C3\%A3odasos-Psic\%C3\%B3logasos-em-Programas-de-MedidasSocioeducativas-em-Meio-Aberto.pdf.

Conselho Federal de Psicologia. (2013). Referências Técnicas sobre a Prática de Psicólogas(os) no Centro de Referência Especializado da Assistência Social - CREAS. CFP. https://site. cfp.org.br/wp-content/uploads/2013/08/CREPOP_CREAS_. pdf
Conselho Federal de Psicologia. (2016a). Demandas do Sistema de Justiça às(aos) Profissionais de Psicologia Lotados nas Políticas Públicas de Saúde e de Assistência Social. CFP. http://site.cfp.org.br/wp-content/uploads/2016/12/ Documento-Base-Demandas-do-Sistema-deJusti\%C3\%A7a_dez2016.pdf

Conselho Federal de Psicologia. (2016b). Nota Técnica n 001/2016 - CONPAS/CFP. Orientações sobre documentos elaborados por psicólogas e psicólogos no âmbito do Sistema Único de Assistência Social (SUAS). CFP. http://conpas.cfp.org.br/ wp-content/uploads/sites/8/2015/01/Nota-T\%C3\%A9cnican\%C2\%BA-001-2016-CONPAS-CFP.pdf

Conselho Regional de Psicologia $11^{\text {a }}$ Região. (2015). Parecer a Respeito de Pedido Oriundos do Ministério Público e do Poder Judiciário aos Profissionais das políticas públicas de Assistência Social e de Saúde - orientações e reflexões. CRP-11. http://www.crp11.org.br/upload/ Parecer\%20Psicologia\%20e\%20Demandas\%20do\%20 Judici\%C3\%A1rio.pdf

Constituição da República Federativa do Brasil. (1988). Presidência da república. http://www.planalto.gov.br/ccivil_03/ constituicao/constituicao.htm

Cordeiro, M. P., \& Curado, J. C. (2017). Psicologia na assistência social: um campo em formação. Psicologia \& Sociedade, 29, e169210. https://doi.org/10.1590/18070310/2017v29169210

Duarte, N. A. S., \& Areosa, S. V. C. (2020). A práxis do psicólogo no contexto da assistência social. Revista Psicologia, Diversidade e Saúde, 9(2), 150-161. http://dx.doi. org/10.17267/2317-3394rpds.v9i2.2798

Gasque, K. C. G. D. (2007). Teoria fundamentada: nova perspectiva à pesquisa exploratória. In S. P. M. Mueller (Org.). Métodos para a pesquisa em Ciência da Informação (pp. 83-118.). Thesaurus.

Gomes, N. S., \& Gonçalves, S. M. M.. (2018). A psicologia na assistência social: considerações sobre o percurso histórico deste "novo" campo. Revista Mosaico, 9(1), 02-09. https://doi.org/10.21727/rm.v9i1.1225

Lei $\mathrm{N}^{\circ}$ 12.435, de 6 de julho de 2011. (2011). Altera a Lei no 8.742, de 7 de dezembro de 1993, que dispõe sobre a organização da Assistência Social. http://www. planalto. gov.br/ccivil_03/_ato2011-2014/2011/lei/l12435.htm 
Lei $n^{\circ}$ 12.594, de 18 de janeiro de 2012. (2012). Institui o Sistema Nacional de Atendimento Socioeducativo (Sinase), regulamenta a execução das medidas socioeducativas destinadas a adolescente que pratique ato infracional; e altera as Leis $n^{\circ}$ s 8.069, de 13 de julho de 1990 (Estatuto da Criança e do Adolescente); 7.560, de 19 de dezembro de 1986, 7.998, de 11 de janeiro de 1990, 5.537, de 21 de novembro de 1968, 8.315, de 23 de dezembro de 1991, 8.706, de 14 de setembro de 1993, os Decretos-Leis n ${ }^{\circ} \mathrm{s}$ 4.048 , de 22 de janeiro de 1942, 8.621, de 10 de janeiro de 1946, e a Consolidação das Leis do Trabalho (CLT), aprovada pelo Decreto-Lei $n^{\circ} 5.452$, de $1^{\circ}$ de maio de 1943. http://www.planalto.gov.br/ccivil 03/ ato20112014/2012/lei/l12594.htm

Lei Nº 8.742, de 7 de dezembro de 1993. (1993). Dispõe sobre a organização da Assistência Social e dá outras providências. http://www.planalto.gov.br/ccivil_03/leis/ 18742.htm

Lei №. 8.069, de 13 de julho de 1990. (1990). Dispõe sobre o Estatuto da Criança e do Adolescente e dá outras providências. https://www.planalto.gov.br/ccivil_03/leis/ L8069.htm

Macedo, J. P., \& Dimenstein, M. (2011). Expansão e interiorização da Psicologia: reorganização dos saberes e poderes na atualidade. Psicologia: Ciência e Profissão, 31(2), 296-313. https://doi.org/10.1590/S1414-98932011000200008

Ministério da Justiça. (2015). Relação entre o Sistema Único de Assistência Social - SUAS e os órgãos do Sistema de Justiça. Ministério da Justiça, Secretaria de Assuntos Legislativos (SAL): IPEA. http://pensando.mj.gov.br/wp-content/ uploads/2015/12/PoD_58_Ana-Paula_web1.pdf

Ministério Público do Paraná. (s. d.). Proteção Social Especial. https://crianca.mppr.mp.br/arquivos/File/suas/creas/ pse_institucional.pdf

Pereira, A. A., \& Zaniani, E. J. M. (2019). O Psicólogo no CRAS: reflexões a partir da análise de encaminhamentos da rede socioassistencial. Anais dos III Congresso Internacional de Política Social e Serviço Social: Desafios Contemporâneos; IV Seminário Nacional de Território e Gestão de Políticas Sociais; III Congresso de Direito à Cidade e Justiça Ambiental. Universidade Estadual de Londrina. https://www. congressoservicosocialuel.com.br/trabalhos2019/ assets/4604-230261-35580-2019-03-31-sem-identificacaoresumo-expandido-congresso-uel-amanda.pdf
Resolução n 33, de 12 de dezembro de 2012. (2012). Aprova a Norma Operacional Básica do Sistema Único de Assistência Social -NOB/SUAS. http://blog.mds.gov.br/ redesuas/resolucao-no-33-de-12-de-dezembro-de-2012/

Resolução n 109, de 11 de novembro de 2009. (2009). Aprova a Tipificação Nacional de Serviços Socioassistenciais. Conselho Nacional de Assistência Social. http://www.mds. gov.br/webarquivos/public/resolucao_CNAS_N109_\%20 2009.pdf.

Resolução CNAS No 145/2004. (2004). Aprova a Política Nacional de Assistência Social. https://www.mds. gov.br/webarquivos/legislacao/assistencia_social/ resolucoes/2004/Resolucao\%20CNAS\%20no\%20145-\%20 de\%2015\%20de\%20outubro\%20de\%202004.pdf

Romagnoli, R. C., \& Silva, B. C. (2019). O cotidiano da intersetorialidade e as relações entre as equipes. Estudos \& Pesquisas em Psicologia, 19(1), 107-126. https://doi. org/10.12957/epp.2019.43009

Sadek, M. T. (Org). (2010). O sistema de justiça. Centro Edelstein de Pesquisas Sociais.

Saramento, S., Rocca, K., Lopes, A. S., Wise, M. L., \& Dal Prá, K. R.. (2018). A judicialização das expressões da questão social na política de assistência social. Anais do XVI Encontro Nacional de Pesquisadores em Serviço Social, 16(1), 1-18. https://www.periodicos.ufes.br/abepss/article/view/22945

Saramento, S. (2018). A judicialização da assistência social em Biguaçu: um estudo a partir da proteção social básica e proteção social especial. [Monografia, Universidade Federal de Santa Catarina]. Repositório Institucional UFSC. https:// repositorio.ufsc.br/handle/123456789/183562 